Research Article

\title{
A study of prevalence of type 2 diabetes mellitus among urban adults of Ballari, India
}

\author{
Sameena Abdul Razak Bekinalkar*, Bellara Raghavendra, T. Gangadhara Goud, Vasantha SC
}

Department of Community Medicine, Vijaynagara Institute of Medical Sciences, Ballari, Karnataka, India

Received: 27 September 2015

Accepted: 10 October 2015

\section{*Correspondence:}

Dr. Sameena Abdul Razak Bekinalkar,

E-mail: drsameenam@gmail.com

Copyright: () the author(s), publisher and licensee Medip Academy. This is an open-access article distributed under the terms of the Creative Commons Attribution Non-Commercial License, which permits unrestricted non-commercial use, distribution, and reproduction in any medium, provided the original work is properly cited.

\section{ABSTRACT}

Background: Diabetes is a major lifestyle disorder, the prevalence of which is increasing globally. India has the unfortunate privilege of being the "Diabetes capital" of the world, more concerning is the fact that diabetes prevalence over the past 4 decades has increased fourfold. Indian studies have shown the prevalence rate of diabetes mellitus to be $2.4 \%$ in rural and 4 to $11 \%$ among urban dwellers due to industrialization and urbanization. There is a paucity of such data in the state and none in Ballari city hence this present study was undertaken to find out the prevalence of type $2 \mathrm{D}$ in urban population of Ballari city.

Methods: This is a cross sectional study conducted in urban wards of Ballari city. The sample of 1412 adults aged above 20 years were included in the study. Cluster sampling technique adopted to select the wards and systematic random sampling was used to select the subjects. Ethical clearance was obtained and written informed consent from respective subjects. Data was collected using pre designed and pretested semistructured questionnaire. Questionnaire included information regarding socio-demographic profile and blood glucose level was measured by glucometer.

Results: The overall prevalence was found to be $12.7 \%$ and prevalence of diabetes mellitus was $15.6 \%$ in males and $10.1 \%$ in case of females.

Conclusions: The prevalence of diabetes mellitus in Ballari city was $12.7 \%$.

Keywords: Diabetes mellitus, Prevalence

\section{INTRODUCTION}

The second half of the twentieth century witnessed major health transitions in the world, propelled by socioeconomic and technological changes which profoundly altered life expectancy and ways of living while creating an unprecedented human capacity to use science to both prolong and enhance life. Among these health transitions, the most globally pervasive change has been the rising burden of non-communicable diseases.

Epidemics of Non-Communicable Diseases (NCD) are presently emerging or accelerating in most developing countries. Even as infections and nutritional deficiencies are receding as leading contributors to death and disability, India too illustrates this health transition, which positions NCDs as a major public health challenge of growing magnitude in the twenty-first century.

A total of 56 million deaths occurred worldwide during 2012. Of these, 38 million were due to NCDs, principally cardiovascular diseases, cancer and chronic respiratory diseases. ${ }^{1}$ Nearly three quarters of these NCD deaths $(28$ million) occurred in low- and middle-income countries. The number of NCD deaths has increased worldwide and in every region since 2000, when there were 31 million NCD deaths. NCD deaths have increased the most in the WHO South-East Asia Region, from 6.7 million in 2000 to 8.5 million in 2012, and in the Western Pacific Region, from 8.6 million to 10.9 million. $^{2}$ 
The leading causes of NCD deaths in 2012 were: cardiovascular diseases (17.5 million deaths, or $46.2 \%$ of NCD deaths), cancers (8.2 million, or $21.7 \%$ of NCD deaths), respiratory diseases, including asthma and chronic obstructive pulmonary disease (4.0 million, or $10.7 \%$ of NCD deaths) and diabetes (1.5 million, or $4 \%$ of NCD deaths). Thus, these four major NCDs were responsible for $82 \%$ of NCD deaths. ${ }^{3}$

In 2012, an estimated 1.5 million deaths were directly caused by diabetes. $^{2}$ In 2008 an estimated 1.2 million people died from consequence of high blood sugar More than $80 \%$ of diabetes deaths occur in low- and middleincome countries. ${ }^{4}$ The second half of the twentieth century witnessed major health transitions in the world, propelled by socio-economic and technological changes which profoundly altered life expectancy and ways of living while creating an unprecedented human capacity to use science to both prolong and enhance life. Among these health transitions, the most globally pervasive change has been the rising burden of non-communicable diseases.

Epidemics of Non-Communicable Diseases (NCD) are presently emerging or accelerating in most developing countries. Even as infections and nutritional deficiencies are receding as leading contributors to death and disability, India too illustrates this health transition, which positions NCDs as a major public health challenge of growing magnitude in the twenty-first century. ${ }^{4}$

A total of 56 million deaths occurred worldwide during 2012. Of these, 38 million were due to NCDs, principally cardiovascular diseases, cancer and chronic respiratory diseases. ${ }^{1}$ Nearly three quarters of these NCD deaths $(28$ million) occurred in low- and middle-income countries. The number of NCD deaths has increased worldwide and in every region since 2000 , when there were 31 million NCD deaths. NCD deaths have increased the most in the WHO South-East Asia Region, from 6.7 million in 2000 to 8.5 million in 2012, and in the Western Pacific Region, from 8.6 million to 10.9 million. $^{2}$

The leading causes of NCD deaths in 2012 were: cardiovascular diseases (17.5 million deaths, or $46.2 \%$ of NCD deaths), cancers (8.2 million, or $21.7 \%$ of NCD deaths), respiratory diseases, including asthma and chronic obstructive pulmonary disease (4.0 million, or $10.7 \%$ of NCD deaths) and diabetes (1.5 million, or $4 \%$ of NCD deaths). Thus, these four major NCDs were responsible for $82 \%$ of NCD deaths. ${ }^{3}$

In 2012, an estimated 1.5 million deaths were directly caused by diabetes. ${ }^{2}$ In 2008 an estimated 1.2 million people died from consequence of high blood sugar more than $80 \%$ of diabetes deaths occur in low- and middleincome countries. ${ }^{4}$

The World Health Organization (WHO) estimated that there were 135 million diabetic individuals in the year
1995 and it has been projected that this number will increase to 300 million by the year $2025 .^{5}$

While T2D poses a huge economic burden to all nations, developing countries bear the highest burden since more than $80 \%$ of cases occur in these countries. As per the International Diabetes Federation (2013), approximately $50 \%$ of all people with diabetes live in just three countries: China (98.4 million), India (65.1 million) and the USA (24.4 million). ${ }^{1}$

The prevalence of diabetes, constituted chiefly by Type 2 Diabetes (T2D), is a global public health threat Prevalence estimates of diabetes and Impaired Glucose Tolerance (IGT) are high for all Asian countries and are expected to increase further in the next two decades. ${ }^{10}$ The present trend indicates that more than $60 \%$ of the world's diabetic population will be in Asia.

India has the unfortunate privilege of being the "Diabetes capital" of the world. More concerning is the fact that diabetes prevalence over the past 4 decades has increased fourfold. ${ }^{7}$ Another interesting phenomena is that Indians who migrate to affluent countries develop very high prevalence rates of 10 to $20 \%$, indicating the high racial predisposition that Indians and other South Asian populations have for diabetes, and which gets expressed whenever we get affluent conditions.

The urban-rural divide in prevalence is narrowing as urbanization is spreading widely, adversely affecting the lifestyle of populations. Asians have a strong ethnic and genetic predisposition for diabetes and have lower thresholds for the environmental risk factors. As a result, they develop diabetes at a younger age and at a lower body mass index and waist circumference when compared with the Western population. The adverse effect of physical inactivity and fatty food are manifested as the increasing rate of overweightness and obesity, even among children. ${ }^{8}$

The first phase of the ICMR-INDIAB study reported the prevalence of diabetes ranging from $5.3 \%$ to $13.6 \%$ in different areas in this study. ${ }^{9}$ Indian studies have shown the prevalence rate of diabetes mellitus to be $2.4 \%$ in rural and 4 to $11 \%$ among urban dwellers due to industrialization and urbanization. ${ }^{7}$ Previously a disease of middle aged and elderly type 2 DM has escalated in all age groups and is now being seen in younger age groups including adolescents especially high risk population. ${ }^{6}$

There is paucity of data on prevalence of diabetes in Karnataka. It is in this background that a study to find out the prevalence of type 2 diabetes mellitus in Ballari city Corporation was planned.

The World Health Organization (WHO) estimated that there were 135 million diabetic individuals in the year 1995 and it has been projected that this number will increase to 300 million by the year $2025 .^{5}$ 
While T2D poses a huge economic burden to all nations, developing countries bear the highest burden since more than $80 \%$ of cases occur in these countries. As per the International Diabetes Federation (2013), approximately $50 \%$ of all people with diabetes live in just three countries: China (98.4 million), India (65.1 million) and the USA (24.4 million ${ }^{1}$ The prevalence of diabetes, constituted chiefly by Type 2 Diabetes (T2D), is a global public health threat Prevalence estimates of diabetes and Impaired Glucose Tolerance (IGT) are high for all Asian countries and are expected to increase further in the next two decades ${ }^{1}$ The present trend indicates that more than $60 \%$ of the world's diabetic population will be in Asia.

India has the unfortunate privilege of being the "Diabetes capital" of the world. More concerning is the fact that diabetes prevalence over the past 4 decades has increased fourfold. ${ }^{7}$ Another interesting phenomena is that Indians who migrate to affluent countries develop very high prevalence rates of 10 to $20 \%$, indicating the high racial predisposition that Indians and other South Asian populations have for diabetes, and which gets expressed whenever we get affluent conditions.

The urban-rural divide in prevalence is narrowing as urbanization is spreading widely, adversely affecting the lifestyle of populations. Asians have a strong ethnic and genetic predisposition for diabetes and have lower thresholds for the environmental risk factors. As a result, they develop diabetes at a younger age and at a lower body mass index and waist circumference when compared with the Western population. The adverse effect of physical inactivity and fatty food are manifested as the increasing rate of overweightness and obesity, even among children. ${ }^{8}$

The first phase of the ICMR-INDIAB study reported the prevalence of diabetes ranging from $5.3 \%$ to $13.6 \%$ in different areas in this study. ${ }^{9}$ Indian studies have shown the prevalence rate of diabetes mellitus to be $2.4 \%$ in rural and 4 to $11 \%$ among urban dwellers due to industrialization and urbanization. ${ }^{7}$ Previously a disease of middle aged and elderly type 2 DM has escalated in all age groups and is now being seen in younger age groups including adolescents especially high risk population. ${ }^{6}$

There is paucity of data on prevalence of diabetes in Karnataka. It is in this background that a study to find out the prevalence of type 2 diabetes mellitus in Ballari city Corporation was planned.

\section{METHODS}

The study was approved by the human ethical committee, Vijaynagara Institute of Medical Sciences, Ballari, Karnataka. This is a cross sectional study conducted in urban wards of Ballari city during the period May 2008 to April 2009. There are 35 wards in Ballari city. Each ward is considered as a cluster, so totally there were 35 clusters. The total population of Ballari according to 2001 census was 315876 . The sampling interval was calculated by dividing the above population with 20 clusters. Then the first cluster is selected for the study by randomly choosing a number less than the sampling interval, the next cluster is selected by adding sampling interval to the randomly chosen number. In this way 20 clusters were selected for this study. The required number of study subjects in each cluster was selected by systematic random sampling technique i.e. 71 subjects per cluster, particular area is selected by using spinning the bottle method, then every fifth house is visited till the required number of subjects are covered. All the members of age group above 20 years of household were included for the study.

The National Urban Diabetes Survey (NUDS), a population based study was conducted in six metropolitan cities across India in 2001 including Bangalore, the study included, ${ }^{11} 216$ subjects aged 20 year and above representative of all socio-economic strata, According to this study prevalence of diabetes mellitus was found to be $12.4 \% .^{10}$ This prevalence is considered to find out the sample size. The sample size estimated using above formula i.e. 706 is doubled to make the sample more representative and compensate for the design effect. So the sample size required for the study was found to be 1412.

The data was collected using a pretested semi structured questionnaire. This questionnaire was tested for appropriateness by conducting a pilot study. Before collection the data consent was taken from the study subjects after explaining the importance of the study in detail. The data was collected by interview method. Questionnaire included information regarding age, sex, education, occupation, religion, socioeconomic status. Blood glucose estimation was done using glucometer under aseptic precautions. Normal: $<200 \mathrm{mg} / \mathrm{dl}$, Diabetes: Signs and symptoms of diabetes mellitus Plus RBS $\geq 200$ $\mathrm{mg} / \mathrm{dl}$. Data was compiled using Microsoft excel software and analyzed using SPSS. Proportion, Chi-square test, Odds ratio was applied wherever necessary.

\section{RESULTS}

A total of 1412 subjects were included in the study formed the study subjects, which included both males $(46.9 \%)$ and females (53\%). Among the 179 subjects with diabetes mellitus, the age of the subjects ranged from 21 to $>70$ years. Majority of them were in the age group of $>51$ years $(63.26 \%)$ (Table 1$)$.

The prevalence of diabetes mellitus is $15.6 \%$ in males and $10.1 \%$ in case of females (Table 2). The prevalence of diabetes was highest in 41-60 years age group i.e. $45.2 \%$ and lowest in the age group 21-30 years i.e. $0.5 \%$. There was a rise in number of diabetic cases from fourth decade of life to fifth decade and then a gradual decline as the age increases. 
Among the study subjects the prevalence of diabetes mellitus was more in males $103(15.6 \%)$ and $76(10.1 \%)$ in females. The present study reveals the prevalence of diabetes among different educational groups and it was observed that the prevalence diabetes mellitus is highest in subjects of SSLC/PUC 34.1\% and lowest in post graduates and above i.e. $4.4 \%$.

Majority of diabetic cases are unemployed i.e. 808 $(57.2 \%)$ and only $59(4.2 \%)$ were semiskilled. The present study shows the prevalence of diabetes mellitus is highest in diabetic cases of upper socioeconomic class i.e. $36.3 \%$ and lowest i.e. $2.8 \%$ in lower class.

Majority of cases are literate $(86 \%)$. Majority of the diabetic cases are unemployed (49.2\%).69.3\% diabetic cases belonged to upper socioeconomic lass.

Table 1: Socio-demographic profile of the study subjects.

\begin{tabular}{|llll|}
\hline Variables & $\begin{array}{l}\text { Male } \\
(\mathbf{n = 6 6 2}) \\
\mathbf{N}(\%)\end{array}$ & $\begin{array}{l}\text { Female } \\
(\mathbf{n = 7 5 0})\end{array}$ & $\begin{array}{l}\text { Total } \\
\mathbf{N}(\mathbf{n}=\mathbf{1 4 1 2})\end{array}$ \\
$\mathbf{N}(\%)$
\end{tabular}

Table 2: Prevalence of diabetes mellitus among study population.

\begin{tabular}{|lll|}
\hline Status & Number & $\begin{array}{l}\text { Prevalence } \\
(\%)\end{array}$ \\
\hline Diabetics & 179 & 12.7 \\
\hline Non diabetics & 1233 & 87.3 \\
\hline Total & 1412 & 100 \\
\hline
\end{tabular}

Table 3: Prevalence of diabetes mellitus among the study subjects.

\begin{tabular}{|c|c|c|c|}
\hline Variable & n $(\%)$ & $95 \% \mathrm{CI}$ & p value \\
\hline \multicolumn{4}{|l|}{ Age (years) } \\
\hline $21-30$ & $2(0.5)$ & $0.08-1.58$ & $\mathrm{p}<0.001$ \\
\hline $31-40$ & $14(5.1)$ & $2.94-8.23$ & \\
\hline $41-50$ & $50(14.6)$ & $11.17-18.67$ & \\
\hline $51-60$ & $66(30.6)$ & $24.69-36.94$ & \\
\hline $61-70$ & $36(33.6)$ & $25.18-42.99$ & \\
\hline$>70$ & $11(18.6)$ & $10.21-30.09$ & \\
\hline \multicolumn{4}{|l|}{ Gender } \\
\hline Male & $103(15.6)$ & $12.95-18.47$ & $\mathrm{p}<0.01$ \\
\hline Female & $76(10.1)$ & $8.12-12.45$ & \\
\hline \multicolumn{4}{|l|}{ Education } \\
\hline $\begin{array}{l}\text { Post graduate } \\
\text { and above }\end{array}$ & $10(16.1)$ & $8.49-26.87$ & $p>0.05$ \\
\hline Graduate & $45(10.6)$ & $7.96-13.85$ & \\
\hline SSLC/PUC & $66(13.7)$ & $10.84-16.98$ & \\
\hline Below SSLC & $32(13.2)$ & $9.38-17.94$ & \\
\hline Illiterate & $26(12.8)$ & $8.72-17.95$ & \\
\hline \multicolumn{4}{|l|}{ Occupation } \\
\hline Professional & $18(19.1)$ & $12.13-28.04$ & $\mathrm{p}<0.05$ \\
\hline Skilled & $57(14.6)$ & $11.37-18.39$ & \\
\hline Semiskilled & $12(20.3)$ & $11.51-32.02$ & \\
\hline Unskilled & $4(6.6)$ & $2.19-15.06$ & \\
\hline Unemployed & $88(10.9)$ & $8.88-13.18$ & \\
\hline $\begin{array}{l}\text { Socio economic } \\
\text { status }\end{array}$ & $\begin{array}{l}\text { Non } \\
\text { diabetics }\end{array}$ & & \\
\hline Upper & $65(36.3)$ & $15.92-24.61$ & $\mathrm{p}<0.001$ \\
\hline Upper middle & $60(33.5)$ & $9.31-14.98$ & \\
\hline Lower middle & $24(13.4)$ & $6.39-13.74$ & \\
\hline Upper lower & $25(14)$ & $5.78-12.28$ & \\
\hline Lower & $5(2.8)$ & $4.28-23.4$ & \\
\hline
\end{tabular}

\section{DISCUSSION}

The present study is a community based cross sectional study carried out in Ballari city, aimed at identifying the prevalence of type $2 \mathrm{DM}$. The present study revealed that the prevalence of type 2 diabetes mellitus is $12.7 \%$. Comparing the results of this study with other studies in India revealed that the prevalence of type 2 diabetes mellitus is consistent high with other studies. The Chennai Urban Population Study (CUPS) which looked at the prevalence of diabetes in two socioeconomic classes in Chennai revealed the overall prevalence of type 2 diabetes was $12 \%$ in the population aged above 20 year. ${ }^{11}$ Another population based study conducted in six large cities from different regions of India, (NUDS) showed that the age standardized prevalence of type 2 diabetes was $12.1 \%$. The prevalence was the highest in Hyderabad $(16.6 \%)$, followed by Chennai $(13.5 \%)$, Bengaluru (12.4\%), Kolkata (11.7\%), New Delhi (11.6\%) and Mumbai (9.3\%). The recent cures study conducted in urban south India reported prevalence of diabetes as $15.5 \%$ which is comparable to our study finding. ${ }^{10}$ 
In this study, the age of the study subjects ranged from 20 to above 70 years. The prevalence of diabetes mellitus is found to be high in the age group 61-70 years i.e. $33.6 \%$ and is least in the age group 21-30 i.e. $0.5 \%$ years. It is also observed that the prevalence of diabetes increases as the age increases. There was a rise in number of diabetic cases from fourth decade of life to fifth decade and then a gradual decline as the age increases. It is also observed that there is an increase in the prevalence of diabetes beyond $7^{\text {th }}$ decade of life, which further confirms that as the age increases the prevalence of diabetes raises. ${ }^{10}$

The prevalence of diabetes mellitus is found to be high in males i.e. $15.6 \%$ and $10.1 \%$ in case of females, with a male to female ratio of $1.4: 1$. Singh TP, Singh AD, Singh TB in their study on prevalence of diabetes mellitus in Manipur reported a higher prevalence of diabetes mellitus in males than in females ${ }^{12}$. Wild $\mathrm{S}$ et al. ${ }^{13}$ in their study also reported higher prevalence of diabetes mellitus in males than females. There was inadequate representation of males in the study sample as most of them were employed and were not available during the survey.

The prevalence of diabetes mellitus was more among post graduate and above i.e. $16.1 \%, 12.8 \%$ among illiterate, $13.7 \%$ in those who had studied up to SSLC/PUC, $13.2 \%$ who had studied below SSLC and $10.6 \%$ in graduate. However level of education is not showing any significant association in our study, this is contradictory to the results of studies by Maty SC et al. and Pan XR et al. which report low level of education as a risk factor of type $2 \mathrm{DM}^{14}$

In the present study majority are unemployed i.e. $49.2 \%$. This may be due to the fact that lack of physical activity among them leading to development of the disease.

The socio-economic status influences occupation, life style and nutrition of social classes which in turn would influence the prevalence and profile of glucose intolerance and diabetic complications. The prevalence of diabetes mellitus in the present study is more among higher socioeconomic class than lower class. The results of this study is supported by study of Ramchandran et al. which reported prevalence of diabetes mellitus to be more among high income group. ${ }^{10}$

Studies in India had revealed that prevalence of diabetes in urban areas was found to be lower in the low socioeconomic groups as compared with higher socioeconomic groups. ${ }^{7}$

Contrast to this in another study Bhatti et al. ${ }^{15}$ had found that the prevalence of diabetes among higher, middle and lower SES group was $21.49 \%, 66.7 \%$ and $12.25 \%$ respectively. A study conducted by V. Connolly et al. had described a significant inverse relation between the prevalence of type $2 \mathrm{DM}$ and socioeconomic status, which is most marked between the ages of 40-69 years. ${ }^{16}$

\section{ACKNOWLEDGEMENTS}

I am indebted to my co-author Mrs Vasanta SC Assistant Professor in Statistics for her valuable suggestions and guidance while designing methodology and biostatistics of the dissertation.

Funding: No funding sources

Conflict of interest: None declared

Ethical approval: The study was approved by the institutional ethics committee of Vijaynagara Institute of Medical Sciences, Ballari

\section{REFERENCES}

1. World Health Organization. Global health estimates: deaths by cause, age, sex and country, 2000-2012. Geneva: WHO; 2014.

2. Alwan A, MacLean DR, Riley LM, d'Espaignet ET, Mathers CD, Stevens GA, et al. Monitoring and surveillance of chronic noncommunicable diseases: progress and capacity in high-burden countries. Lancet. 2010;376:1861-8.

3. WHO. The global burden of disease: 2004 update. Geneva: World Health Organization; 2008.

4. World Health Organization. Global health estimates: deaths by cause, age, sex and country, 2000-2012. Geneva: WHO; 2014.

5. World Health Organization. Global health estimates: deaths by cause, age, sex and country, 2000-2012. Geneva: WHO; 2014.

6. Ramachandran A, Snehalatha C, Kapur A, Vijay V, Mohan V, Das AK, et al. Diabetes Epidemiology Study Group in India (DESI): high prevalence of diabetes and impaired glucose tolerance in IndiaNational Urban Diabetes Survey (NUDS). Diabetologia. 2001;44:1094-101.

7. WHO. WHO Expert Committee on DM. Technical Report Series 646. Geneva: WHO; 1980: 312.

8. Iyer SR. Type 2 diabetes express highway, where is the ' $\mathrm{U}$ ' turn? J Assoc Physicians India. 2003;51:495-500.

9. Anjana RM, Pradeepa R, Deepa M, Datta M, Sudha V, Unnikrishnan R, et al. Prevalence of diabetes and prediabetes (impaired fasting glucose and/or impaired glucose tolerance) in urban and rural India: phase I results of the Indian Council of Medical Research-INdia DIABetes (ICMR-INDIAB) study. Diabetologia. 2011 Dec;54(12):3022-7.

10. IDF. Diabetes Atlas. A Book. 6th ed. Belgium: IDF; 2013. Available at: https://www.idf.org/sites/default/files/EN_6E_Atlas _Full_0.pdf.

11. Mohan V, Shanthirani S, Deepa R, Premalatha G, Sastry NG, Saroja R. Intra-urban differences in the prevalence of the metabolic syndrome in southern India - The Chennai Urban Population Study (CUPS No. 4). Diabet Med. 2001;18:280-7.

12. Singh RB, Bajaj S, Niaz MA, Rastogi SS, Moshiri M. Prevalence of type 2 diabetes mellitus and risk of 
hypertension and coronary artery disease in rural and urban population with low rates of obesity. Int $\mathbf{J}$ Cardiol. 1998;66:65-72.

13. Wild S, Sicree R, Roglic G, King H, Green A. Global prevalence of diabetes: estimates for the year 2000 and projections for 2030. Diabetes Care. 2004;27:1047-53.

14. Pan XR, Yang WY, Li GW, Liu J. Prevalence of diabetes and its risk factors in China, 1994. National Diabetes Prevention and Control Co-operative Group. Diabetes Care. 1997;20:1664-9.

15. Bhatti JS, Bhatti GK, Joshi A, Rai S, Mastana SS, Ralhan SK, et al. Identification of the risk factors for the high prevalence of type 2 diabetes and its complications in a Punjabi population: North Indian Diabetes Study: a case-control study. Int J Diabetes Dev Country. 2007;27(4):108-15.

16. Connolly V, Unwin N, Sherriff P, Bilous R, Kelly W. Diabetes prevalence and socioeconomic status: a population based study showing increased prevalence of type 2 diabetes mellitus in deprived areas. J Epidemiol Community Health. 2000;54(3):173-7.

Cite this article as: Bekinalkar SAR, Raghavendra B, Gangadhara Goud T, Vasantha SC. A study of prevalence of type 2 diabetes mellitus among urban adults of Ballari, India. Int J Community Med Public Health 2015;2:660-5. 